\title{
Profile of circulating MicroRNAs in low density lipoprotein uptake: literature review
}

\author{
Perfil dos MicroRNAs circulantes na absorção de lipoproteínas de baixa densidade: \\ revisão da literatura
}
Perfil de los MicroRNAs circulantes en la absorción de lipoproteínas de baja densidad: revisión de la literatura

\begin{abstract}
Maria Elisabete Silva Santos ${ }^{1}$, Ricardo Sousa de Oliveira Paraense ${ }^{1}$, Ricardo Roberto de Souza Fonseca ${ }^{1}$, Danilo Leôncio Aguiar Pereira ${ }^{1}$, Carlos Eduardo Silva Cordeiro ${ }^{1}$, Thaís Letícia dos Santos Corrêa ${ }^{2}$, Luciana Carvalho Imbiriba ${ }^{1}$, Patrícia do Socorro Queiroz Feio ${ }^{3}$, Emília Maria Paiva de Amorim $^{4}$, Erik Artur Cortinhas Alves ${ }^{5 *}$.
\end{abstract}

\begin{abstract}
Objective: Delineate a profile of circulating miRNA that interfere with the uptake of C-LDL through the regulation of LDL, APOB-100 and PCSK9 genes that can be used as biomarkers for prognosis and treatment of atherosclerosis. Bibliography review: The atherosclerosis, a chronic and inflammatory disease that occurs when there are high levels of LDL on plasma. This important risk factor for development of cardiovascular disease is the main cause of death worldwide. The miRNAs have recently emerged as potential biomarkers and therapeutic target for lipid metabolism disorders. In this review, we will provide profile of circulating miRNAs that have demonstrated being regulators of PCSK9, LDL and APOB100 genes. Recent work has identified the miR-148, miR-128, miR-27a/b, miR-185, miR-301, miR-130 as important regulators of this pathway because they decrease supply of LDL receptors through interaction with PCSK9. Final considerations: We conclude that, when overexpressed, miR-148a, mir128 and miR-27a/b, miR-122 and miR-34 are related to decrease in LDL, facilitating occurrence of atherosclerosis. Detection of miRNAs profile could be used in the future as a biomarker for disturbs linked to c-LDL uptake and in future anti-miRNAs therapies may be used in the treatment of atherosclerosis.
\end{abstract}

Keywords: Circulating MicroRNA, Low-density lipoprotein, Atherosclerosis.

\section{RESUMO}

Objetivo: Delinear um perfil de MicroRNAs circulantes que interferem na captação de C- LDL através da regulação dos genes LDL, APOB-100 e PCSK9 que podem ser utilizados como biomarcadores para prognóstico e tratamento da aterosclerose. Revisão bibliográfica: A aterosclerose, uma doença inflamatória e crônica que ocorre quando há altos níveis de LDL no plasma. Esse importante fator de risco para o desenvolvimento de doenças cardiovasculares. Os microRNAs surgiram como potenciais biomarcadores e alvo terapêutico para distúrbios do metabolismo lipídico. Nesta revisão, encontramos um perfil de miRNAs circulantes que demonstraram ser reguladores dos genes PCSK9, LDL e APOB100. Trabalhos recentes identificaram os miR-148, miR-128, miR-27a / b, miR-185, miR-301 e miR-130 como importantes reguladores dessa via, pois diminuem a oferta de receptores de LDL por meio da interação com o PCSK9. Considerações finais: Quando superexpressos, miR-148a, mir128 e miR-27a/b, miR-122 e miR-34 estão relacionados à diminuição do LDL, facilitando a ocorrência de aterosclerose. A detecção do perfil de miRNAs pode ser usada

\footnotetext{
${ }^{1}$ Universidade Federal do Pará (UFPA), Belém - PA.

2 Instituto Federal do Pará (IFPA), Belém - PA.

${ }^{3}$ Universidade Estadual de Campinas (UNICAMP), Campinas - SP.

${ }^{4}$ Universidade Federal do Rio Grande do Norte (UFRN), Natal - RN.

5 Universidade do Estado do Pará (UEPA), Belém - PA. *E-mail: cortinhasalves45@hotmail.com
} 
no futuro como um biomarcador de distúrbios relacionados à captação de c-LDL e em futuras terapias antimiRNAs podem ser usadas no tratamento da aterosclerose.

Palavras-chave: MicroRNA circulante, Lipoproteína de baixa densidade, Aterosclerose.

\section{RESUMEN}

Objetivo: El objetivo es describir un perfil de microRNA (miRNA) circulantes que interfieren con la absorción de c-LDL a través de la regulación de los genes LDL, APOB-100 y PCSK9 que pueden usarse como biomarcadores para el pronóstico y tratamiento de la aterosclerosis. Revisión bibliográfica: aterosclerosis, importante factor de riesgo para enfermedades cardiovasculares, es una enfermedad inflamatoria crónica que ocurre cuando hay altos niveles de LDL en el plasma. Los miRNA han surgido recientemente como posibles biomarcadores y objetivos terapéuticos para los trastornos del metabolismo lipídico. En esta revisión, proporcionaremos un perfil de miRNAs circulantes que se ha demostrado que regulan los genes PCSK9, LDL y APOB100. Estudios han identificado miR-148, miR-128, miR-27a / b, miR-185, miR-301 y miR-130 como reguladores importantes de esta vía, ya que reducen el suministro de receptores de LDL a través de la interacción con PCSK9. Consideraciones finales: cuando sobreexpresa, miR-148a, mir128 y miR-27a / b, miR-122 y miR-34 están relacionados con la disminución de LDL, lo que facilita la aterosclerosis. El perfil de miARN puede usarse en el futuro como biomarcadores de trastornos relacionados con la captación de C-LDL y terapias anti-miARN pueden aparecer para el tratamiento de la aterosclerosis.

Palabras clave: MicroRNA circulante, Lipoproteína de baja densidad, Aterosclerosis

\section{INTRODUCTION}

According to World Health Organization (WHO) around 17 million people die worldwide each year in consequence of cardiovascular diseases, being atherosclerosis the main cause. Atherosclerosis, the thickening of arterial wall caused by the accumulation of lipids and it is closely related to pathologies as coronaries syndrome, ischemic heart disease, cerebrovascular disease and peripheral vascular disease, all caused by obstruction arteries due to the accumulation of Low-Density Lipoprotein (LDL) (CHISTIAKOV DA, et al., 2017).

A risk factor for the development of atherosclerosis and the elevation of LDL levels on plasma. The LDL contains apolipoprotein B100 (APOB100) which acts as a ligand of LDL receptor (LDLR) in hepatic cells. Ligand-receptor interaction (LDLR and APOB-100) make LDL lipoproteins being removed of blood flow and absorbed by hepatocytes by endocytosis, decreasing the risk of atherosclerosis (EVERETT BM, et al., 2015).

A supply of LDL receptors on the cell surface is regulated at the transactional level by Protein convertase subtilisin/kexin type 9 (PCSK9) and transcriptional powders by activation of independent mechanisms involving PCSK9 that bind to the RLDL leading to its internalization and inducible Degrader of LDL (IDOL) receptor which is an E3 ubiquitin and binds to RLDL and mediates its ubiquitination, both of which are degraded by the LDLR and consequently there is an increase in plasma LDL (EVERETT BM, et al., 2015; DE GONZALOCALVO D, et al., 2017; FU C, et al., 2018).

Studies have reported the importance as microRNAs in regulation of cholesterol metabolism (HUANG Y, et al., 2016; WANG Y, et al., 2017). The microRNAs are non-coding single-stranded RNAs of proteins (22$24 \mathrm{pb}$ ) very important in post transcriptional genetic regulation, it acts in modulation of gene expression and intercellular communication, thus, interfering in a variety of physiological functions among these the cholesterol metabolism then contributing to progression of atherosclerosis.

Therefore, a profile of surrounding miRNAs that can be used as markers of lipid metabolism disorders becomes essential for the prognosis of atherosclerosis. In addition, these same markers can contribute to development of specific drugs which turns the treatment and diagnosis more specific and effective. (WEN D, et al., 2015; HUNTLEY RP, et al., 2016; PACHOLEWSKA A, et al., 2016; ARYAL B, et al., 2017). The aim of this review is to delineate a profile of circulating miRNAs that interfere with the uptake of LDL through the regulation of LDLR, APOB-100 and PCSK9 genes that can be used as potential biomarkers for the prognosis and treatment of atherosclerosis. 


\section{BIBLIOGRAPHY REVIEW}

\section{Biogenesis of miRNAs}

Currently, more than 1.500 miRNAs have been described, previous studies have suggested that up to $60 \%$ of our genes can be regulated by miRNAs, and as a consequence, these small endogenous silencers act as regulators of a number of processes such as cell proliferation, development, angiogenesis and cholesterol metabolism (TIAN N, et al., 2014; BAO MH, et al., 2018).

The miRNAs are transcribed from intronic regions of genes encoding proteins or intergenic regions. This transcription is performed by RNA polymerase II, generating a long primary transcript (pri-miRNA) that are stacked and polyadenylated (HUANG Y, et al., 2016; WANG Y, et al., 2017). These transcripts are capable of folding into hairpin structures that are recognized by RNA binding proteins DGCR8 (DiGeorge syndrome critical region gene 8). DGCRs carry the miRNAs to Drosha, an endonuclease that cleaves the duplex clusters of primiRNAs and transforms them into pre-miRNAs (70 nucleotides) (DE GONZALO-CALVO D, et al., 2017; FU C, et al., 2018). Pre-miRNAs bind RNA-exporter proteins, such as exportin-5, and are transported rapidly into the cytoplasm (Figure 1) (WU CY, et al., 2018).

Once in the cytoplasm, the pre-miRNA is processed by a complex of proteins called RNA-Induced Silencing Complex (RISC) formed by Dicer and Argonaute. Dicer is a double-stranded endonuclease that binds and cleaves the pre-miRNA in 21-23 bp segments forming mature miRNAs, which are brought by the RISC to the target mRNA to be paired with the 3'-untranslated region (3'UTR) promoting gene silencing. The perfect match between mRNA and miRNA causes degradation of the target mRNA, but these complementarities may also be imperfect when one or more bases are poorly paired, which represses the translation. This non-specificity causes a single miRNA to have several target mRNAs that can regulate the expression of several genes (Figure 1) (PACHOLEWSKA A, et al., 2016; ARYAL B, et al., 2017).

Figure 1 - Biosynthesis scheme and mechanism of action of miRNAs.

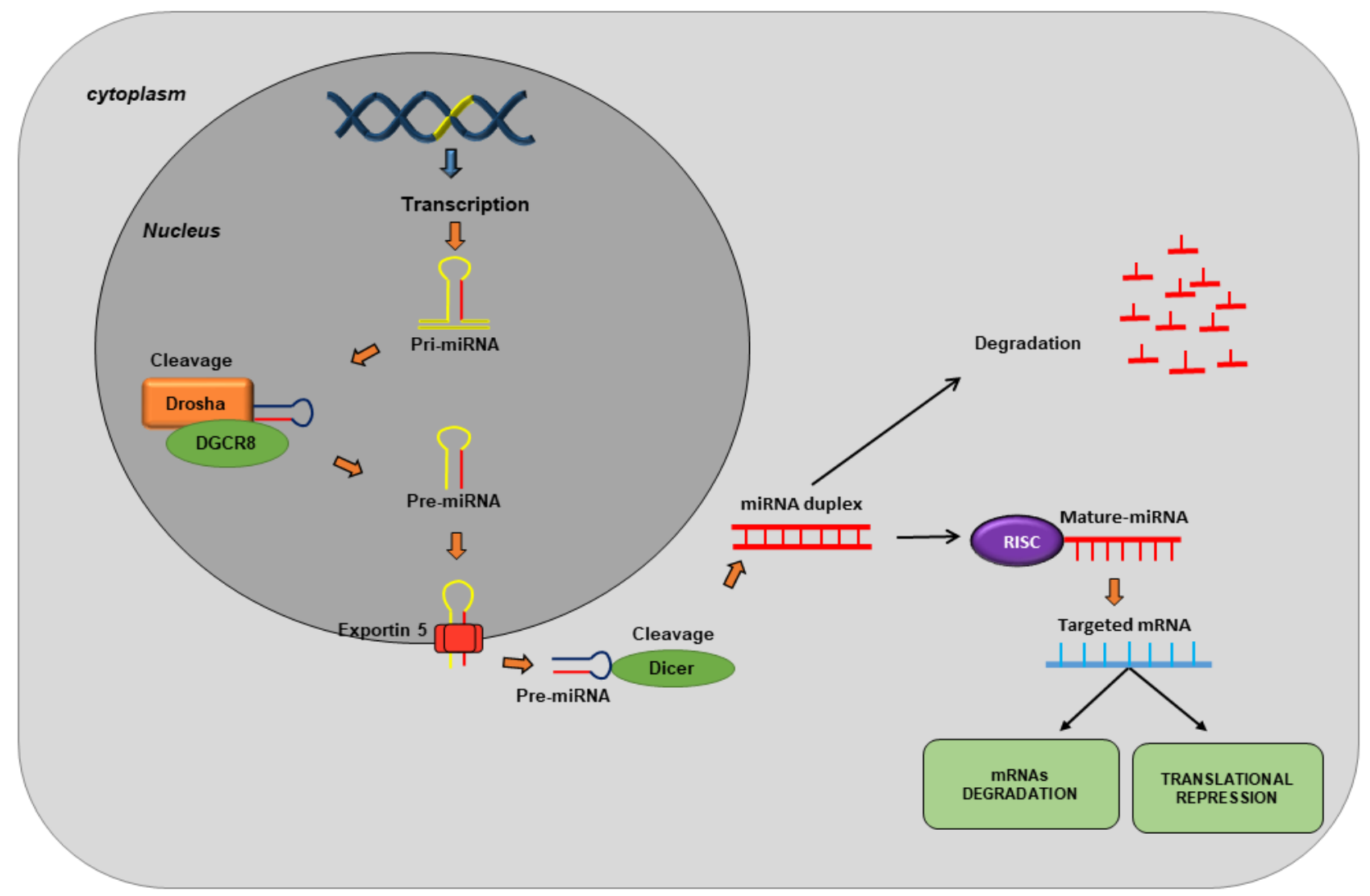

Fonte: Santos MES, et al., 2020. 


\section{Circulating miRNAs as Potential Biomarkers and Therapeutic Targets to Cardiovascular Disease (CVDs)}

It was previously believed that miRNA expression was limited to intracellular endogenous activity. It is now known that miRNAs can be synthesized in specific cells and subsequently secreted into plasma, which facilitates the communication between cells of different tissues.

The small size of miRNA molecules, and the fact that they are transported into lipoproteins such as exosomes and micro vesicles, apoptotic bodies and protein complexes, are characteristics that protect these small molecules from the action of plasmatic RNAses and make the microRNAs more stable than mRNAs and DNAs in plasma (WAGSCHAL A, et al., 2015; ZHANG T, et al., 2015).

Studies show that numerous miRNAs have deregulated expression profiles that vary with pathology and degree of severity. Since then several studies have demonstrated the expression of circulating miRNAs in CVDs, acute myocardial infarction, coronary diseases, dyslipidemia, obesity, diabetes, hypertension and metabolic syndrome. Thus, a new field of miRNA investigations was opened as potential biomarkers for the prognosis and therapeutic targets for the treatment of CVDs (ROBINSON JG, et al., 2015; TATE R, et al., 2015).

\section{Uptake of LDL (Low-Density Lipoprotein)}

Uptake of LDL by hepatocytes occurs through the interaction of several genes, among them apolipoprotein B-100, a protein present in the membrane of LDL vesicles, which has the function of binding to LDLR, allowing the absorption and degradation of LDL by the liver. However, when there are no LDL receptors, metabolism of LDL does not occur and consequently there is an increase in plasma of c-LDL levels favoring the onset of atherosclerosis (BAO MH, et al., 2018).

Availability of LDLR for cholesterol uptake occurs through two pathways, the first one is regulated according to the need for cholesterol that the liver cells present. This regulation occurs through the activation of the binding proteins to the sterol regulatory element (SREBPs). There are three isoforms of SREBP: SREBP1a, SREBP1c (encoded by the SREBF1 gene) and SREBP2 (encoded by the SREBF2 gene) (ARYAL B, et al., 2017; WU CY, et al., 2018). In intracellular medium the SREBP1 and SREBP2 are regulated by cholesterol levels. SREBP1 is responsible for transcription of genes involved in synthesis of fatty acids, phospholipids and triacylglycerols being regulated by insulin and oxysterols. SREBP2 are the main regulator of cholesterol biosynthesis (ZHANG T, et al., 2015; HUNTLEY RP, et al., 2016; PACHOLEWSKA A, et al., 2016).

These transcription factors, when inactive, remain attached to the nuclear envelope and to the membranes of the endoplasmic reticulum. In cells with low levels of sterols, SREBP2s are targeted to the Golgi complex where they are processed to their mature nuclear form. They are then translocated to the nucleus where the DNA sequences responsible for the synthesis of enzymes involved in the biosynthesis of stereoisomers such as hydroxy-3-methylglutaryl CoA reductase (HMGCR), LDLR and PCSK9. Elevation of the stereoisomers levels inhibits the maturation of SREBP2 and consequently the inhibition of the synthesis of the same in a feedback system (KIM JO, et al., 2015; LEE TH, et al., 2015; KUAN YC, et al., 2016).

The second pathway that regulates the availability of LDLR occurs through PCSK9, a serine protein that is expressed and secreted primarily in the liver, kidney and brain. PCSK9 is synthesized as a soluble zymogen (proPCSK9) and requires autocatalysis for its activation and maturation. Once activated, PCSK9 can follow two pathways for the degradation of LDLR. The first, PCSK9 can bind to LDLR right after synthesis and direct to lysosomal vesicles. In the second route, surrounding PCSK9 binds to low-density lipoprotein (LDLR) receptors present on the surface of hepatocytes, causing their internalization and degradation within lysosomal vesicles. This affects availability of LDLR on the cell surface and consequently concentration of LDL in plasma (MOZAFFARIAN D, et al., 2015; NICULESCU LS, et al., 2015; LI M, et al., 2015; POIRIER S, et al., 2015).

Normal functioning of LDL uptake pathway is important for maintenance of normal plasmatic cholesterol levels. Hypercholesterolemia occurs through the excess of plasma LDL, representing one of the most important risk factors for the development of atherosclerosis (POIRIER S, et al., 2015). 


\section{Role of miRNAs in the Regulation of PCSK9 and LDLR}

Recently several studies have shown that modulation of specific miRNAs can directly influence lipid metabolism through post-transcriptional control of key genes such as LDLR. Currently several miRNAs have been correlated with LDLR expression levels, among which are miR-27a/b, miR-148a, miR-130b, miR-128-1, and miR-185 (PANKRATZ F, et al., 2018; WANG J, et al., 2018).

\section{miR-148a, miR-130b and miR-128-1}

The paper of Goedeke L, et al. (2015) shown the miR-148a as first miRNA adjuster plasma c-LDL levels in vivo. The miR-148 is located in an intergenic region of chromosome 7 and is predominantly expressed in liver. The miR-130b, mir-128-1 and miR-301b also were found next of Single Nucleotide Polymorphism (SNPs) associated with c-LDL, Triglycerides, elevation levels. However, despite this proximity the microRNAs are not associated with these SNPs.

In a study by Wagschal A, et al. (2015) the expression of miR-148a and miR-130b was increased in the liver of mice fed with a high fat diet, suggesting an evolutionarily conserved binding to the function of lipid metabolism. miR-148a is targeted as a key regulator in hepatic cholesterol clearance modulating the expression of LDLR and ATP Binding Cassette Subfamily A Member 1 (ABCA1) of HDL. These studies emphasize the therapeutic potential of these miRNAs in the control of C-LDL levels in dyslipidemias (NICULESCU LS, et al., 2015; WANG J, et al., 2018).

The miR-128 is located on region of intron 18. Study in vivo demonstrated that treatment with antisense inhibition of miR-128 and miR-148a in Apoe -/- mice alters cholesterol metabolism through of elevated expression of ABCA1 and LDLR, increased LDL clearance in comparison with controls. In addition, was demonstrated that elevated levels of miR-128 inhibit expression of insulin receptors contribute to insulin resistance, and metabolic syndrome (LI M, et al., 2015; WAGSCHAL A, et al., 2015).

Studies indicate that miR-301b also participate in the regulation of LDLR. Wagschal A, et al. (2015) emphasizes the role of miR-301b in controlling the expression of genes involved in hepatic lipogenesis with the salt-inducible kinase 1 (SIK1), gene responsible for activating SREBP1c. This regulation mechanism interferes with the supply of LDLRs in plasmatic membrane and consequently plasma c-LDL levels. It has been shown that in HepG2 cells transfected with miR-301b, there was a decrease in the uptake of fluorescently labeled c-LDL (Dil-LDL) compared to non-transfected cells, suggesting that these miRNAs modulate the uptake of c-LDL.

\section{miR-27a/b}

MiR-27b is expressed in the liver and is recently related to the negative regulation of plasma cholesterol levels. Li P, et al. (2018) reports that miR-27a/b can influence metabolic pathways of efflux, influx, esterification and cholesterol hydrolysis by regulating several genes (BAO MH, et al., 2018).

LDLR is one of miR-27a/b targets. A study with wild-type mice using AAV8 vectors showed that the elevation of miR-27b levels by 50 -fold resulted in a reduction in ABCA 1 expression by $50 \%$ and LDLR by $20 \%$, however, there was not change in levels of Cholesterol or triglycerides. To determine the effects of inhibition of miR-27b on circulating lipids, Goedeke L, et al. (2015) fed wild-type mice with a lipid-rich diet and treated them with $5 \mathrm{mg} / \mathrm{kg}$ injections of anti-27b LNA oligonucleotides, after treatment, there was increased by 10$20 \%$ in expression of ABCA1 and LDLR in the hepatocytes (Figure 2).

ALVAREZ ML, et al. (2015) found that overexpression of miR-27 in HepG2 cells caused a $40 \%$ decrease in the supply of LDLR, however, it was observed that interaction between miR-27 and PCSK9 increased in three-fold the expression of PCSK9.

ZHOU L, et al. (2016) observed that miR-27a regulates lipid metabolism by inhibiting the expression of several genes, such as the SREBP1, SREBP2 transcription factors responsible for the activation of LDLR and PCSK9 transcription, as well as the inhibition of apolipoproteins expression ApoA1, ApoB100 and ApoE3. Thus, miR-27a regulates lipid metabolism by reducing lipid synthesis and lipid secretion of cells. These results reinforce how miR-27b regulates the expression of important genes in lipid metabolism and may be a potential target for treatment of CVD. 
LPL gene encodes the enzyme lipoprotein lipase, which aids the breakdown of lipoproteins, which normally carry fat molecules from the intestine into the bloodstream. Macrophage-derived lipoprotein lipase (LPL) plays a key role in accelerating lipid accumulation and secretion of proinflammatory cytokines in the atherosclerotic process. XIE W, et al. (2016) provides evidence that a novel anti-atherogenic role of miR-27 is closely related to the reduction of lipid accumulation and inflammatory response through the negative regulation of LPL gene expression, suggesting a potential strategy for the diagnosis and treatment of atherosclerosis.

Figure 2 - Role of miRNAs in the regulation of target genes leading to the development of atherosclerosis.
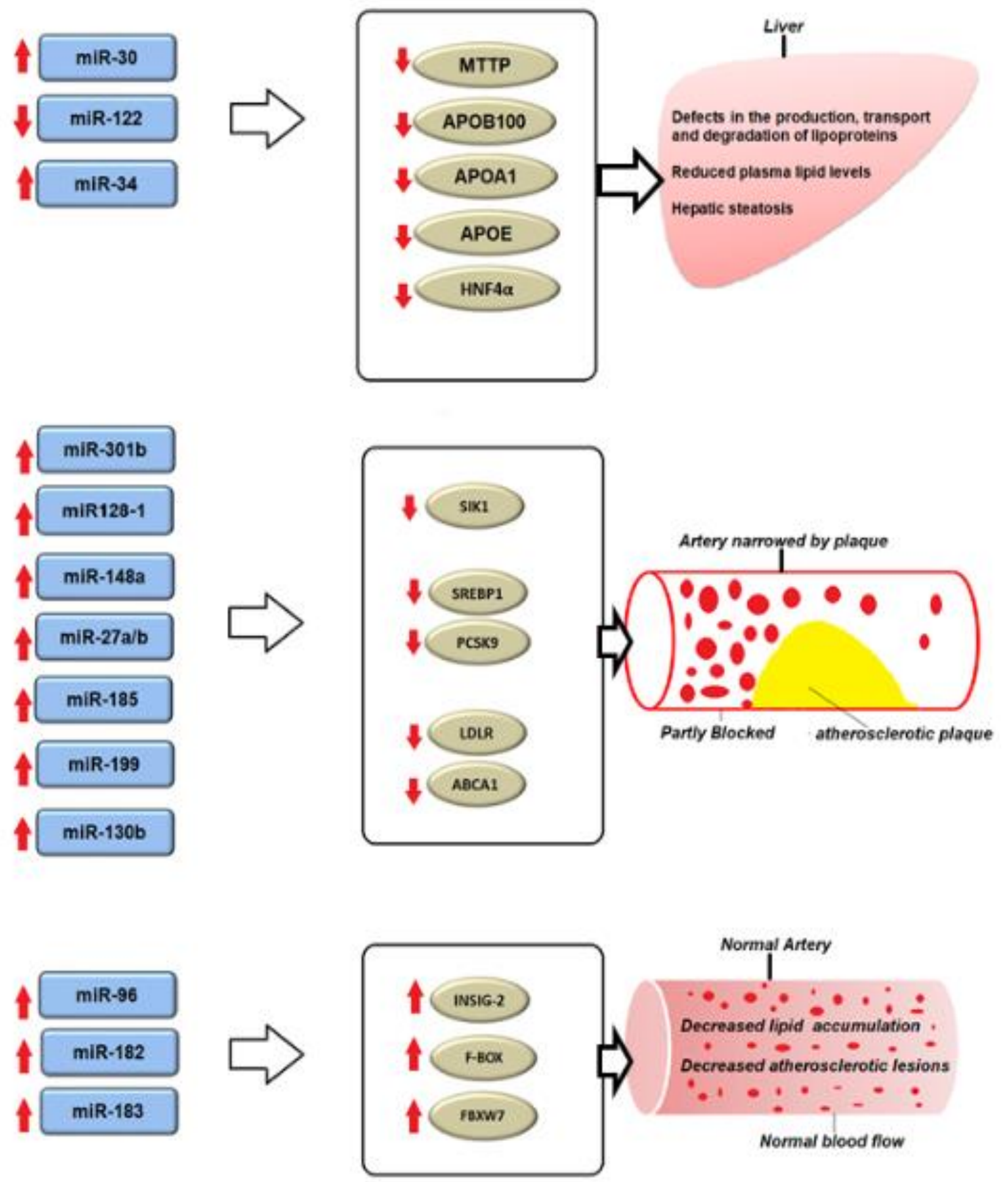

Fonte: Santos MES, et al., 2020. 


\section{miR-185}

MiR-185 is located on chromosome 22q11.2. Recent work on miR-185 has demonstrated an important role in regulating various targets that play a role in cardiac hypertrophy, an adaptive mechanism of the heart, in response to increased activity or functional overload (YU M, et al., 2016).

Overexpression of miR-185 causes decreased expression of HMGCR and LDLR receptor. ALVAREZ ML, et al. (2015) evidenced that mice with elevated cholesterol had levels of miR-185 expression five times higher than the control group. Induced inhibition of miR-185 caused increased expression of the SREBP-2, LDLR and PCSK9 genes and HMG-CoA reductase activity (Figure 2). In addition, miR-185 expression was found to be tightly regulated by SREBP-1C, through its binding to a single sterol response element in the miR-185 promoter (ALVAREZ ML, et al., 2015; GOEDEKE L, et al., 2015).

Study of transfection demonstrated that in human hepatic Huh7 cells which the overexpressed miR-199 advance inhibition of expression of endocytosis as Clathrin Heavy Chain (CLTC), Ras-related protein (Rab5A) and Ras-related protein Rab-21 (Rab21) and RLDL when compared to cells transfected with a non-target control. In addition, they also demonstrated inhibition of endogenous miR-199 promotes an increased in the synthesis of LDLR, Rab5A and Rab21 pertains suggesting that miR-199a / b-5p plays a physiological role in the regulation of cellular endocytosis and synthesis LDLR (GOEDEKE L, et al., 2015; HAAS M, et al., 2016).

The miR-96/182/183 locus is conserved in humans and regulate levels of lipids through of decrease the expression of Insulin induced gene 2 (Insig-2) and F-Box And WD Repeat Domain Containing 7 (Fbxw7), these proteins negative regulate Levels of SREBP-2. The culture of HeLa cells treated with miR- miR-96, miR-182, miR-183 demonstrated the Nuclear SREBP-1 was increased similarly by each individual miRNA or the combination the three microRNAs Therefore, an SREBP-responsive locus miR-96/182/183 contributes to regulatory for intracellular lipid homeostasis (HUANG Y, et al., 2016).

\section{Role of miRNAs in the Regulation of Apoliprotein APOB}

The APOB-100 are important components of the VLDL lipoproteins, and LDL, has the function of binding to LDL receptors for the absorption of plasma cholesterol by the liver, playing a key role in cholesterol metabolism. After its synthesis, APOB-100 is translocated by the membrane of the endoplasmic reticulum (ER) to the addition of small molecules of lipids and also to avoid their degradation. It is in the Endoplasmic Renticulum (RE) that APOB100 binds to Microsomal triglyceride transfer protein (MTTP), which adds more phospholipids to APOB100 for the assembly and secretion of lipoproteins (HUNTLEY RP, et al., 2016; PACHOLEWSKA A, et al., 2016).

The microRNA is a major regulator of glucose metabolism, oxidative stress, arterial hypertension and processes such as adipogenesis, cardiac hypertrophy and ischemia, indicating that its expression may be essential for normal cardiac function and structure (HUANG Y, et al., 2016; WANG Y, et al., 2017).

The importance of miRNAs in the assembly and secretion of lipoproteins containing APOB is now known. However, it is not yet known specifically which miRNAs are involved in the regulation of this pathway. miR-30c is a major regulator of glucose metabolism, oxidative stress, arterial hypertension and processes such as adipogenesis, cardiac hypertrophy and ischemia, indicating that its expression may be essential for normal cardiac function and structure (ZHANG T, et al., 2015; HUNTLEY RP, et al., 2016).

\section{miR-30}

One of the functions recently discovered, and therefore little described, is the role of miR-30 in the regulation of lipid metabolism. Previous studies have shown that overexpression of miR-30c decreases hepatic MTTP synthesis. WANG L, et al. (2019) observed that inhibition of miR-30c in Huh7 hepatocytes increased MTTP expression.

The secretion and function of APOB100 and lipoproteins remained unchanged, evidencing how miR-30c is an important regulator of plasma c-LDL levels (Figure 2). Overexpression of miR-30c mediated by lentivirus, decreased hepatic MTT expression. The absence of formation of MTTP-APOB complex promotes the degradation of APOB in the lumen of the endoplasmic reticulum, which causes compromise in the VLDL assembly (XU Y, et al., 2015; XIE W, et al., 2016). 
It was observed that mice fed for three weeks on a high fat diet and exhibiting lentivirus-mediated overexpression of miR-30c, remained low c-LDL levels compared to controls. MiR-30c contributed to the decrease of atherosclerosis in APOE-/- mice, demonstrating that it is important for the regulation of hepatic and plasma lipid concentrations through the inhibition of lipid synthesis and secretion of lipoproteins containing APOB100 rich in triglycerides. WANG L, et al. (2019) suggested that miR-30 analogues can be used to treat hypercholesterolemia and atherosclerosis in patients who are intolerant to statins.

miR-122

The most abundant microRNA in the liver is miR-122, accounting for about $70 \%$ of all expressed miRNA, responsible for maintaining the hepatic cell phenotype. miR-122 also plays an important role in the regulation of the MTTP and APOB100 pathways. Mice with deletion in the coding region of miR-122 remained with low plasma LDL levels but developed hepatic steatosis (Figure 2).

Inhibition of miR-122 causes assembly impairment and lipoprotein secretion due to inhibition of various genes, such as MTTP which is important in preventing the degradation and lipidation of nascent APOB during the generation of VLDL in the liver.

In a study conducted by de LEE TH, et al. (2015), the influence of miR-122 expression on the differentiation of pluripotent stem cells in sperm-like cells in vitro was investigated. The miR-122 interferes in the expression of lipoproteins like APOB and APOA causing the abnormal development of spermatozoa (ROBINSON JG, et al., 2015; TATE R, et al., 2015; ARYAL B, et al., 2017).

Several studies associate the inhibition of miR-122 expression in mice with the reduction of plasma cholesterol and triglyceride levels when compared to controls. According to WU CY, et al. (2018), this decrease in plasma C-LDL is a consequence of increased fatty acid oxidation and decreased hepatic cholesterol synthesis caused by the inhibition of miR-122 through the regulation of fatty acid oxidation related genes.

Gene expression studies emphasize the importance of miR-122 in the synthesis of VLDL by regulating genes such as MTTP, APOB, APOE, LDLR and SREP1c, demonstrating miR-122 as a potential target for the treatment of lipid disorders (LI P, et al., 2018).

\section{miR-34}

Another miRNA that has been reported in the regulation of APOB is miR-34. Recent studies have shown that this miRNA regulates lipid metabolism through genes such as Hepatocyte nuclear factor 4 alpha (HNF4 $\alpha$ ), a hepatic hormone-nucleolar receptor that regulates APOB expression. The expression of miR-34 decreases the secretion of LDL, VLDL, which results in hepatic steatosis and decrease in plasma lipid levels.

Thus, the increase of miR-34a reduces the expression of HNF4 $\alpha$ in the liver by attenuating the development of atherosclerosis in APOE -/- or LDLR -/- mice. These data indicate that the miR-34a-HNF4a pathway is activated under common metabolic stress conditions and may play a role in plasma lipoprotein metabolism and atherosclerosis protection (Figure 2) (DE GONZALO-CALVO D, et al., 2017; FU C, et al., 2018).

\section{FINAL CONSIDERATIONS}

In this review, we highlighted the role of miR-30c, miR-34 and miR-122 in decreasing plasma c-LDL by inhibiting secretion of lipoproteins containing APOB100. However, miR-34 and miR-122 were also related a risk factor for cardiovascular diseases. While overexpression of miR-148a, miR-27a/b and miR-185 were associated with a decrease in the supply of LDLR, leading to the onset of hypercholesterolemic main cause of atherosclerosis. Detection of the expression profile of these mi-RNAS can be used as a biomarker for disorders linked to c-LDL uptake and future anti-miRNA therapies may be used in the treatment of atherosclerosis. Given the importance of these miRNAs, additional studies are needed to characterize other miRNAs in the pathway PCSK9-LDLR-APOB100 that may have contributed to the atherosclerotic disease. 


\section{REFERÊNCIAS}

1. ALVAREZ ML, et al. MicroRNA-27a decreases the level and efficiency of the LDL receptor and contributes to the dysregulation of cholesterol homeostasis. Atherosclerosis. 2015, 242(2), 595-604.

2. ARYAL B, et al. MicroRNAs and Lipid Metabolism. Curr Opin Lipidol. 2017 Jun;28(3):273-280.

3. BAO MH, et al. Long Noncoding RNA LINC00657 Acting as a miR-590-3p Sponge to Facilitate Low Concentration Oxidized Low-Density Lipoprotein-Induced Angiogenesis. Mol Pharmacol. 2018 Apr;93(4):368-375.

4. BERNARDO BC, et al. Therapeutic inhibition of the miR-34 family attenuates pathological cardiac remodeling and improves heart function. Proc. Natl. Acad. Sci. U. S. A. 2012, 109(43), 17615-17620.

5. CHISTIAKOV DA, et al. Mechanisms of Foam Cell Formation in Atherosclerosis. J Mol Med (Berl). 2017 Nov;95(11):11531165.

6. DE GONZALO-CALVO D, et al. Translating the microRNA signature of microlipoproteins derived from human coronary artery smooth muscle cells in patients with familial hypercholesterolemia and coronary artery disease. J Mol Cell Cardiol. 2017, 106, 55-67.

7. EVERETT BM, et al. Reducing LDL with PCSK9 Inhibitors--The Clinical Benefit of Lipid Drugs. N Engl J Med. 2015, v. 373, p. $1588-1591$.

8. FU C, et al. Notoginsenoside R1 Protects HUVEC Against Oxidized Low Density Lipoprotein (Ox-LDL)-Induced Atherogenic Response via Down-Regulating miR-132. Cell Physiol Biochem. 2018;51(4):1739-1750.

9. GOEDEKE L, et al. MicroRNA-148a regulates LDL receptor and ABCA1 expression to control circulating lipoprotein levels. Nat. Med. 2015, 21(11), 1280-1289.

10. GOEDEKE L, et al. miR-27b inhibits LDLR and ABCA1 expression but does not influence plasma and hepatic lipid levels in mice. Atherosclerosis. 2015, 243(2), 499-509.

11. HAAS M, et al. Role of Proprotein Convertase Subtilisin/Kexin Type 9 in Nephrotic Syndrome-Associated Hypercholesterolemia. Circulation. 2016, 134(1), 61-72.

12. HUANG Y, et al Circulating miR-30 is related to carotid artery atherosclerosis. Clin Exp Hypertens. 2016, 38(5), 489-494.

13. HUNTLEY RP, et al. Guidelines for the functional annotation of microRNAs using the Gene Ontology. RNA. 2016,22 (5), 667-676.

14. KIM JO, et al. miR-185 plays an anti-hypertrophic role in the heart via multiple targets in the calcium-signaling pathways. PLoS One. 2015, 10(3), e0122509.

15. KUAN YC, et al. Heat Shock Protein 90 Modulates Lipid Homeostasis by Regulating the Stability and Function of Sterol Regulatory Element-binding Protein (SREBP) and SREBP Cleavage-activating Protein. J Biol Chem. 2016, 292(7), 301630128.

16. LEE TH, et al. MicroRNA-122 associates with serum apolipoprotein B but not liver fibrosis markers in $\mathrm{CHC}$ genotype 1 infection. J Med Virol. 2015, 87(10), 1722-1726.

17. LI M, et al. MicroRNA-185-5p mediates regulation of SREBP2 expression by hepatitis $\mathrm{C}$ virus core protein. World $\mathrm{J}$ Gastroenterol. 2015, 21(15), 4517-4525.

18. LI P, et al. MicroRNA-30c-5p Inhibits NLRP3 Inflammasome-Mediated Endothelial Cell Pyroptosis Through FOXO3 DownRegulation in Atherosclerosis. Biochem Biophys Res Commun. 2018 Sep 18;503(4):2833-2840.

19. MOZAFFARIAN D, et al. Heart Disease and Stroke Statistics-2015 Update: American Heart Association. 2015, 131(4), e29322.

20. NICULESCU LS, et al. MiR-486 and miR-92a Identified in Circulating HDL Discriminate between Stable and Vulnerable Coronary Artery Disease Patients. PLoS One. 2015, 10(10), e0140958.

21. PACHOLEWSKA A, et al. Novel equine tissue miRNAs and breed-related miRNA expressed in serum. BMC Genomics. 2016, 17(1), 831-846.

22. PANKRATZ F, et al. MicroRNA-100 Suppresses Chronic Vascular Inflammation by Stimulation of Endothelial Autophagy. Circ Res. 2018 Feb 2;122(3):417-432.

23. POIRIER S, et al. GRP94 Regulates Circulating Cholesterol Levels through Blockade of PCSK9-Induced LDLR Degradation. Cell Rep. 2015, 13(10), 2064-2071.

24. ROBINSON JG, et al. Efficacy and safety of alirocumab in reducing lipids and cardiovascular events. N Engl J Med. 2015, 372(16), 1489-1499.

25. TATE R, et al. Regulation of lipid metabolism by microRNAs. Curr Opin Lipidol. 2015, 26(3), 243-244.

26. TIAN N, et al. Curcumin regulates the metabolism of low density lipoproteins by improving the C-to-U RNA editing efficiency of apolipoprotein B in primary rat hepatocytes. Mol. Med. Rep. 2014, 9(1), 132-136.

27. WAGSCHAL A, et al. Genome-wide identification of microRNAs regulating cholesterol and triglyceride homeostasis. Nat. Med. 2015, 21(11), 1290-1297.

28. WANG J, et al. MicroRNA-214-3p: A Link Between Autophagy and Endothelial Cell Dysfunction in Atherosclerosis. Acta Physiol (Oxf). 2018 Mar;222(3).

29. WANG L, et al. CircRNA/IncRNA-miRNA-mRNA Network in Oxidized, Low-Density, Lipoprotein-Induced Foam Cells. DNA Cell Biol. 2019; 38(12):1499-1511.

30. WANG Y, et al. MicroRNA-9 Inhibits NLRP3 Inflammasome Activation in Human Atherosclerosis Inflammation Cell Models Through the JAK1/STAT Signaling Pathway. Cell Physiol Biochem. 2017;41(4):1555-1571.

31. WEN D, et al. Circulating microRNA-223 as a potential biomarker for obesity. Obes Res Clin Pract. 2015, 9(4), 398-404.

32. WU CY, et al. MicroRNA-328 Ameliorates Oxidized Low-Density Lipoprotein-Induced Endothelial Cells Injury Through Targeting HMGB1 in Atherosclerosis. J Cell Biochem. 2018 Oct 15.

33. XIE W, et al. MicroRNA-27 Prevents Atherosclerosis by Suppressing Lipoprotein Lipase-Induced Lipid Accumulation and Inflammatory Response in Apolipoprotein E Knockout Mice. PLoS One. 2016, 11(6), 1-20.

34. $\mathrm{XU} \mathrm{Y}$, et al. A metabolic stress-inducible miR-34a-HNF4alpha pathway regulates lipid and lipoprotein metabolism. Nat. Commun. 2015, 6, 7466.

35. YU M, et al. Circulating miR-185 might be a novel biomarker for clinical outcome in patients with dilated cardiomyopathy. Sci Rep. 2016, 6, 33580.

36. ZHANG T, et al. Circulating miR-126 is a potential biomarker to predict the onset of type 2 diabetes mellitus in susceptible individuals. Biochem Biophys Res Commun. 2015, 463(1-2), 60-63.

37. ZHOU L, et al. MicroRNAs regulating apolipoprotein B-containing lipoprotein production. Biochim. BBA - Molecular and cell biology of lipids. 2016, 1861(12B), 2062-2068. 